\title{
دور الحوكمة المحلية الرشيدة في تفعيل البدائل للإنفاق الحكومي
}

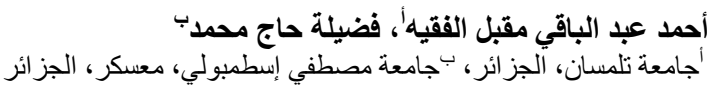

تتقسم وحدة العمل الى عدد من الأقسام الفرعية والتي يمثل كل منها جانباً وظيفياً محدداً. ومعظم المنظمات تميل الى وجود وحدات

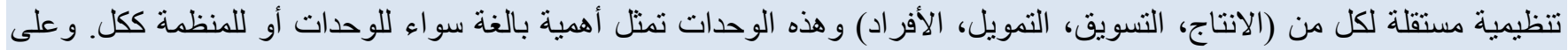

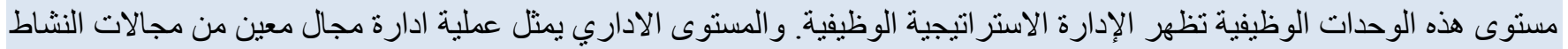

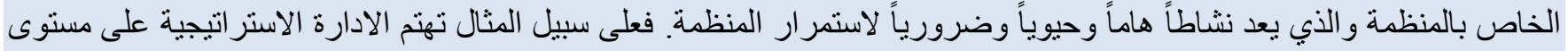

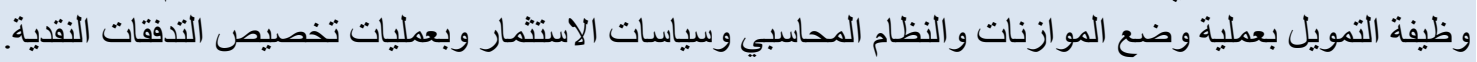
الكلمات المفتاحية : الحوكمة، التتمية المحلية_الصفقات العمومية، الانفاق الحكومي

\section{RESEARCH ARTICLE}

\section{The Role of Good Local Governance in Activating Alternatives to Government Spending}

\author{
Ahmed Elfakiha ${ }^{\mathrm{a}}$, Fadila Hadj Mohamed ${ }^{\mathrm{b}}$ \\ ${ }^{a}$ Universite of Tlemcen - Algeria, ${ }^{b}$ Mustapha Stamboul University Mascara - Algeria
}

\begin{abstract}
The work unit is divided into a number of subsections, each of which represents a specific job aspect. Most of the organizations tend to have independent organizational units for each of (production, marketing, finance, and individuals) and these units represent great importance, whether for the units or for the organization as a whole. At the level of these functional units, functional strategic management can be found. The administrative level represents the process of managing a specific area of the organization's activity, which is a vital and necessary activity for the organization's continuity. For example, strategic management at the level of the finance function is concerned with the process of developing budgets, the accounting system, investment policies, and cash flow allocations.
\end{abstract}

Keywords: governance, local development, public deals, government spending

\section{1. مقدمة:}

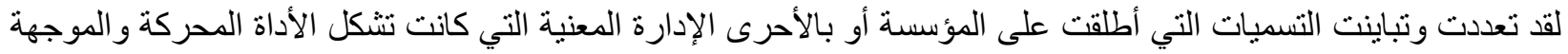

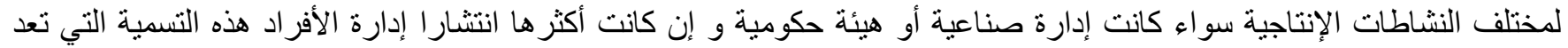

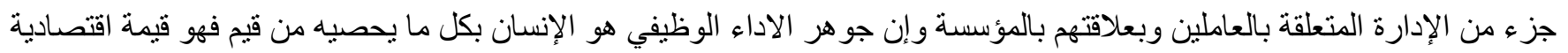




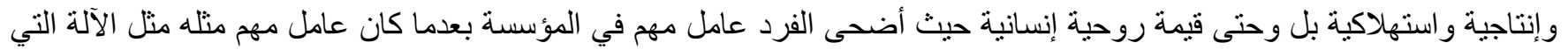

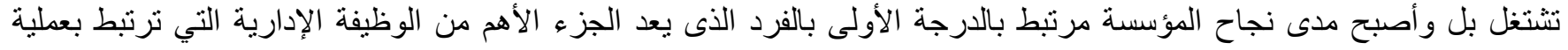

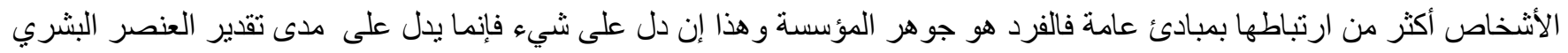

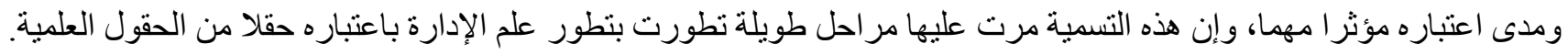

1.1

الى أي مدى تم تفعيل دور الحوكمة المحلية الرشيدة في نجاعة البديل للإنفاق الحكومي؟

2. تحديد المفاهيم و المتغيرات:

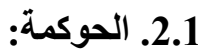

نظام يتم بموجبه إخضاع نشاط المؤسسات إلى مجموعة من القو انين والنظم و القرار ات التي تهدف إلى تحقيق الجودة و التميز

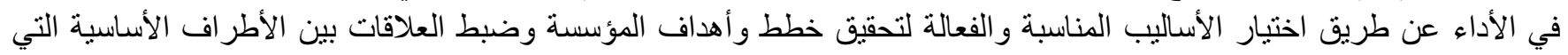

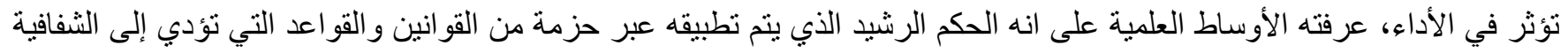

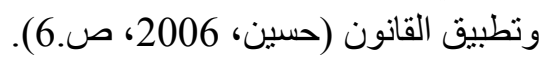

2.2.

أن الحوكمة السليمة والإدارة الرشيدة لمؤسسات الدولة نؤدي إلى تحقيق أهدافها و الخطوة الأولى في عملية إنشاء نظام

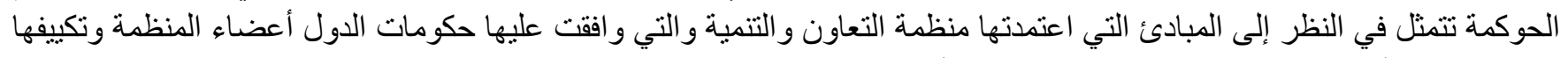
بما يخدم تحقق أهداف مؤسسات الدولة المختلفة لئلة وكما يأتي-:

1- المحافظة على أموال الدولة (حق الثعب):تعد المحافظة على المال العام الهدف الأول لجميع الأطر اف وبما يتلائم مع التغيرات الحاصلة في البيئة الاقتصادية عمو ماً والبيئة الاقتصادية الإلية المحلية خصوصا.

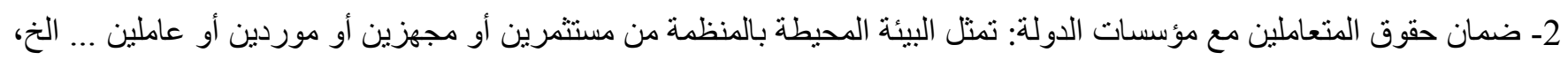

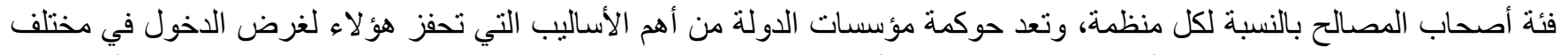

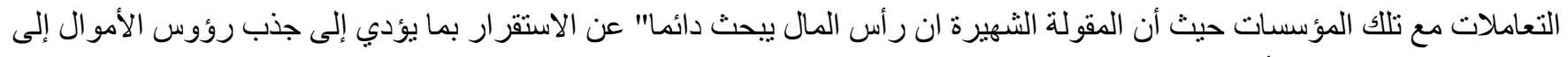
المنظمات التي تقف على أرض صلبة وتعمل ضمن معايير وقو انين ثابتة مما يشيع روح الاطمئنان بالنسبة لكافة المتعاملين معها.

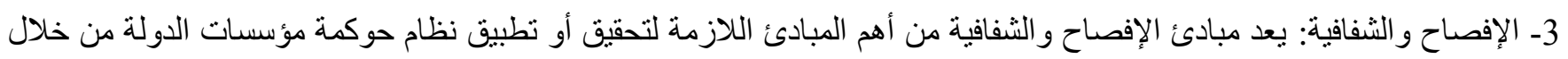

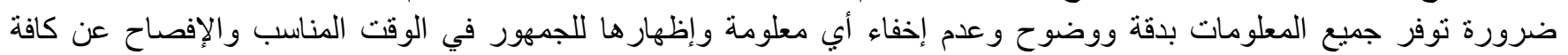
البيانات المالية والمعلومات الأخرى وتقارير الأداء و الملكية وأسلوب استخدام الصلاحيات وأن يتم الإفصاح عن المعلومات الآتية-:

$$
\text { ب. ب. أهدادئ المؤسسة . }
$$

ج. الرواتب و المز ايا الممنوحة إلى المدراء العامين.

د. المخاطر التي من المتوقع أن تحيط بعمل المؤسسة.

ه. البيانات المالية.

و. المسائل المادية المتصلة بالعاملين. 
ز. هياكل وسياسات الحوكمة المعتمدة.

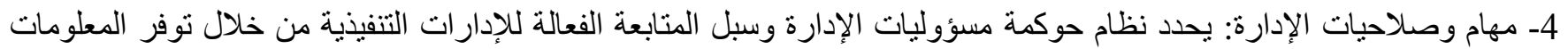

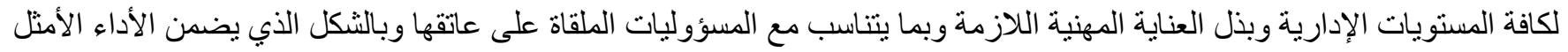

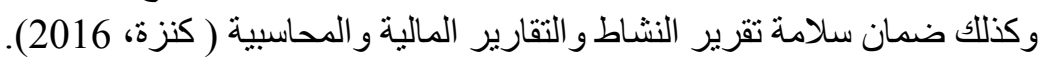

2.3. - 2.3 أهداف الحوكمة:

تسعى الحوكمة من خلال الأهداف إلى تحقيق رفع الكفاءة أداء المؤسسات ووضع الأنظمة الكفيلة بتخفيف أو تقليل الغش

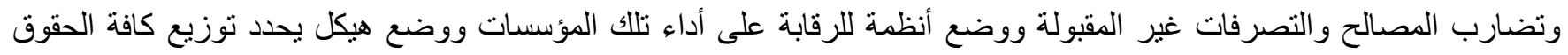
و المسؤوليات وتحديد القواعد و الإجراءات و المخططات المتعلقة بسير العمل داخل المؤسسة ويمكن أجمال الأهداف التي يمكن تحقيقها نتيجة تطبيق نظم الحوكمة بما يأني:

1- تحقيق الثفافية و العدالة ومنح الحق في مساءلة إدارة المؤسسة للجهات المعنية. 2- تحقيق الحماية اللازمة للملكية العامة مع مر اعاة مصالح المتعاملين مع مؤسسات الدولة المختلفة و الحد من استغلال السلطة في تفضيل المصلحة العامة.

3- تحقيق فرصة مر اجعة الأداء من خارج أعضاء الإدارة التنفيذية تكون لها مهام واختصاصات وصلاحيات لتحقيق رقابة فعالة ومستقلة. 4- زيادة الثقة في أدارة الاقتصاد القومي بما بساهم في رفع معدلات الاستثمار وتحقيق معدلات نمو مرتفعة في الدخل القومي( حماد، . (2005 الثكل رقم (1): خصائص نظام حوكمة المؤسسات

\section{الثكل رقم (010): خصائص نظام حوكمة المؤسسات}

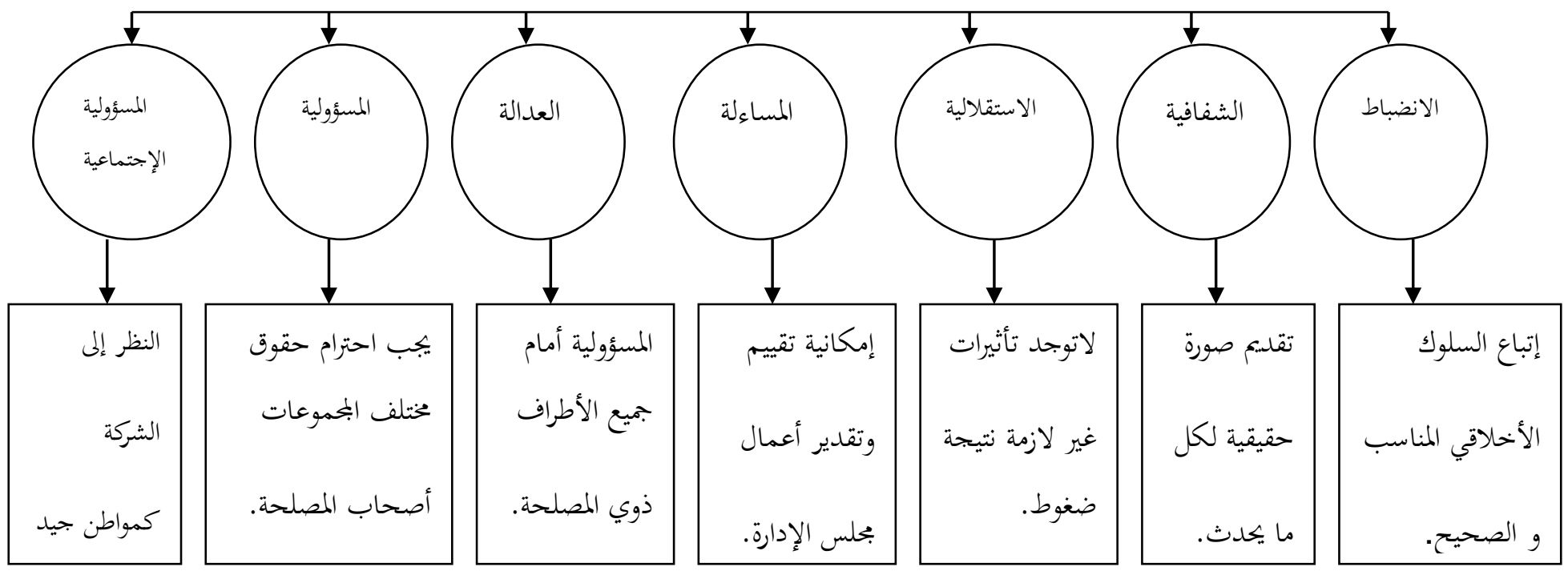

المصدر: عبد الله بن منصور، (2013). 
2.4. الاصلاح الاداري من منظور الحوكمة المحلية الرشيدة:

ـ تهيئة البيئة الخارجية لتنفيذ استراتيجيات الاصلاح عن طريق تفعيل مختلف الاجراءات الادارية والاجتماعية والسياسية، وهذا قصد نجاح بر امج الاصلاح.

ـ انشاء اجهزة ادارية للاصطلاح تكون على عاتقها ادارة ومر اقبة عمليات الاصلاح و التطعيم الاداري بمبادئ الحوكمة المحلية الرشيدة

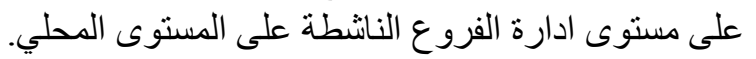
ـ ارنباط جهاز الاصلاح الاداري بقاعدة مشاركة واسعة مع باقي الوحدات التنفيذية الناشطة مركزيا ومحليا. ـ اعتماد جهاز الاصلاح على عناصر مادية و بشرية مرتفعة الفعالية و الكفاءة و التدريب. ـ اعتماد مبدا الانتشار الاداري على مستوى كل الوحدات الادارية المحلية، مع التركيز على التنسيق الاداري عن طريق جهاز اصلاح

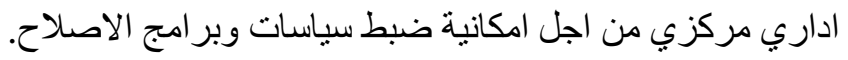

ـ مر اعاة خصوصية كل منطقة ادارية محلية، مع ضرورة التقليل من مستويات التسيير المركزية بين الفروع المحلية المعتمدة. - ربط عمليات الاصلاح الاداري بمفاهيم الحوكمة المحلية الرشيدة .

ـ ارتباط اجهزة الاصلاح الاداري مباشرة بالقيادات العليا المسيرة على مستوى الدولة (رشيد، 1981).

2.5. التسيير العمومي الجديد من منظور الحوكمة المحلية الرشيدة:

تعتبر مدرسة الادارة العمومية الحديثة فلسفة للإدارة حيث اخذت الحكومات تطبيقها من ثمانينيات القرن العشرين لتحديث القطاع العام، والادارة العامة الجديدة مصطلح و اسع النطاق شديد التعقيد، حيث عرف هذا الندة النموذج بعدة مسميات مختلفة، الادارة العامة

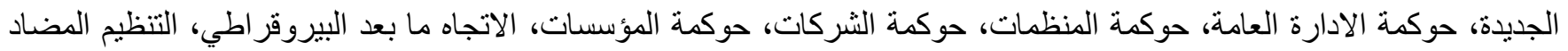

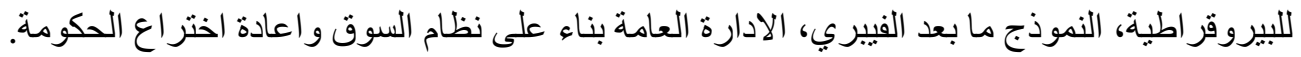

ويعتبر تطور الادارة العامة الحديثة واحد من اكثر الاتجاهات الدولية المعاصرة اللافتة للنظر، فقد هيمنت الادارة العمومية

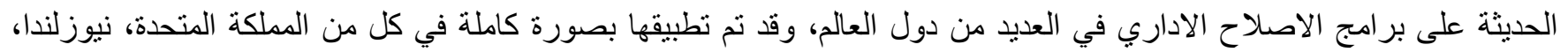

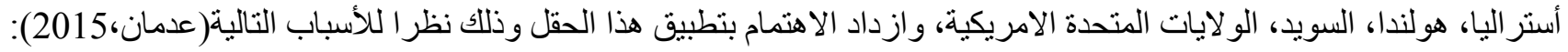
ان الاجهزة الادارية الحكومية لم ينظر اليها على انها تقوم بوظائف الاكر اه المادي و المعنوي باستخدام السلطة السياسية. ـ فثل التسيير الكلاسيكي للبيروقر اطيات الحكومية و ضرورة مو اكبة التغيير ات البيئية المتسار عة الوتيرة. ـ اعتبار اساس قوة الدولة التحكم في النظام الاداري ذو الفعالية والكفاءة العالية.

ـ اهمية تفعيل دور الادارة من اجل تحقيق التنمية المستدامة، باعتبار الادارة العامة والادارة المحلية

بالخصوص المتغير الضابط والمتحكم في عملية التنمية اضافة الى باقي العو امل الاخرى الاجتماعية والثقافية والسياسية و الحضارية. و اهداف التسيير العمومي الجديد اصلاح بيروقراطية الادارة بما يتماثى ومفاهيم ادارة الحوكمة الرشيدة والتكيف مع التطورات

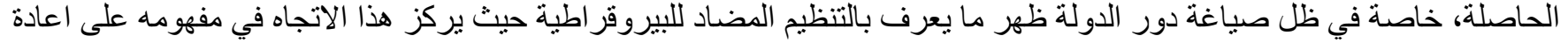

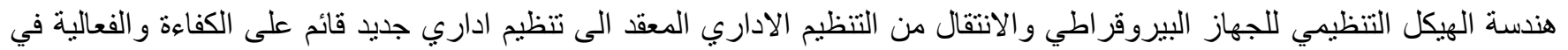

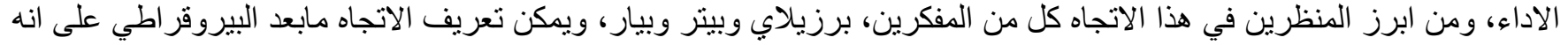

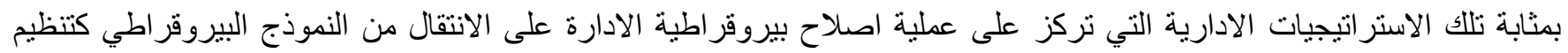

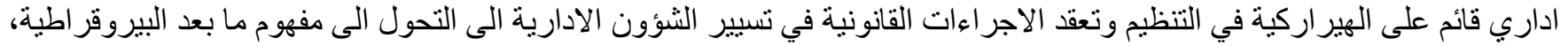


ابي الاتتقال من جهاز اداري تقليدي قائم على خصائص واساليب النمط الفيبري الى بيروقر اطية حديثة متضمنة معايير التسيير العمومي

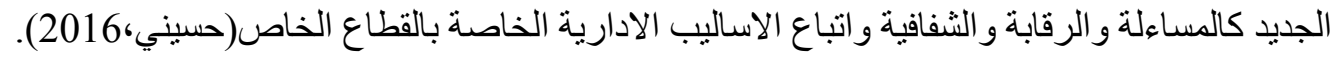

3. الحوكمة الاكترونية:

1- الادارة الالكترونية من منظور الحوكمة المحلية الرشيدة: هناك عدة تعاريف للحوكمة الالكترونية نذكر منها: هي: "استخدام تكنولوجيات المعلومات و الاتصال في الادار ات العمومية، متبو عا بتغييرات على مستوى التنظيم و استعدادات جديدة للأفر اد" هي:" مجمو عة من الافعال و السلوكيات التي تندرج ضمنها المعلومات الالكترونية للإدارة اين تكون الثفافية و النجاعة هي القاعدة

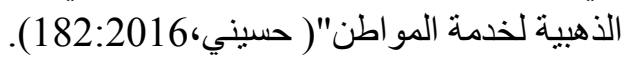
ومن اهداف الحوكمة الالكترونية من منظور الحوكمة المحلية الرشيدة: أـ اهداف الحوكمة الالكترونية على مستوى تفعيل سياسات الاجهزة الادارية : ـ تفعيل مختلف ركائز و اسس الحوكمة المحلية الرشيدة كالمساءلة، الثفافية، الاستجابة، النزاهة، تقريب الادارة من المواطن، الفعالية، الكفاءة ،العصرنة مغنة ـ اعادة تنظيم العمل الاداري و تأهيل الكوادر البشرية وتدريبهم على استعمال التقنيات الحديثة بهدف التنمية الادارية. ـ تحقيق الاتصال الفعال بين الموظف الحكومي وطالب الخدمة العامة . ـالفعالية والكفاءة وتقديم الخدمة وفقا لمعايير الجودة الادارية . ـ التنافسية فيما بين الاجهزة الادارية المحلية. ـ استيعاب ومعالجة كم هائل من المعلومات و الانشغالات و الثكاوي . ـ تجسيد التسبير الالكتروني الذي يهدف الى ضبط الوثائق الادارية وتبسيط العمليات الادارية . ترقية الحوار و التشاور، بهدف تعزيز الديمقر اطية التشاركية، واشر الك لمواطن في تسيير المشاريع التنموية (عدمان،2015). بـ اهداف الحوكمة الالكترونية على مس توى الاطر اف الفاعلة المحلية: -تقديم الخدمات العامة للأطر اف المحلية عن طريق الاتصال بينها وبين الحكومة والجهاز الاداري. من خلال تكنولوجيا المعلومات و الاتصال. ـ تخفيف الاعباء على المو اطنين وتخفيف الجهد المطلوب لأنهاء المعاملات الادارية . ـ تحقيق العدالة في تقديم الخدمة للمو اطن بذات الدقة و التكلفة و الجودة، الى جانب المساو اة في المعاملات الادارية. ـ مشاركة وادماج مختلف الفو اعل المحلية في عملية صناعة القرار ات عن طريق تكنولوجيا الاتصالات انترنيت، مواقع الكترونية، موقع شبكات التو اصل الاجتماعي. ـ تعزيز الديمقر اطية التشاركية الاكترونية وهذا بفتح مختلف قنوات الاتصال للاطر اف المحلية لابداء الآراء و المساءلة والاطلاع على والى

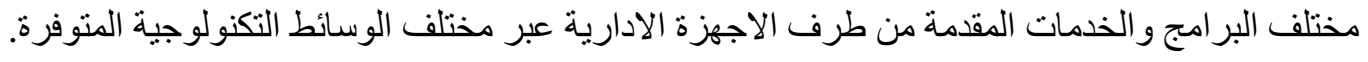


ـ تعتبر التقنيات الحديثة في الاتصال من اهم الوسائل الحديثة في التأثير واجراء التحولات والاصداحات السياسية والادارية، مثل ما

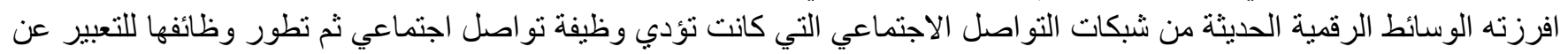
مشاعر الاغتراب السياسي وتغيير الحكومات( حسيني، 2016).

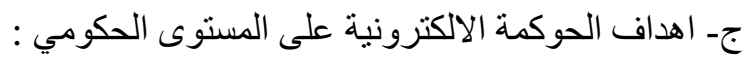
ويشمل الاتصال بين الموظفين داخل المنظمة الادارية او الاتصال بين الادارة المركزية وباقي الادارات المحلية من اجل تحقيق

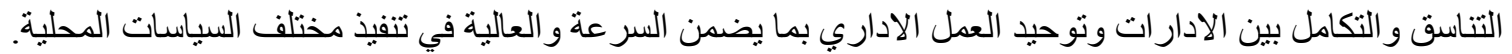
المساهمة في تفعيل الاستراتيجيات العامة للدولة و المتمثلة في الاساس في تحقيق التنمية المستدامة وتعزيز المحافظة على . السير العادي للنسق الاجتماعي .

\section{4. استراتيجية الحوكمة المحلية الرشيدة في تفعيل السياسات العامة المحلية التنموية:}

تستهدف التنمية المحلية تحقيق التوازن التنموي بين مختلف المناطق وفي مقدمة مهامها تنفيذ مشروعات البنى الأساسية ضمن

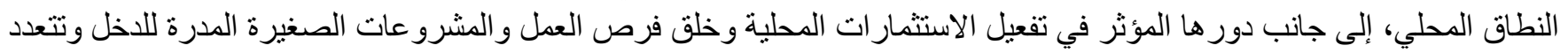

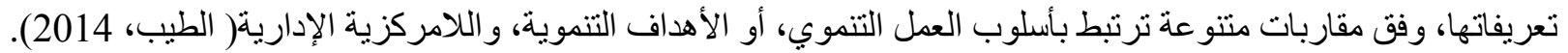
يمكن النظر للتنمية المحلية على أنها الاستغلال الأمثل للموارد المادية والبشرية المتاحة، وتوظيفها للرقي بالإنسان وتحسين

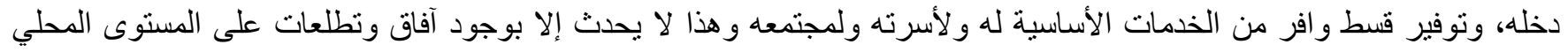

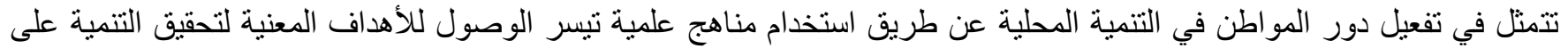

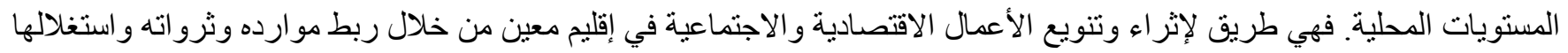

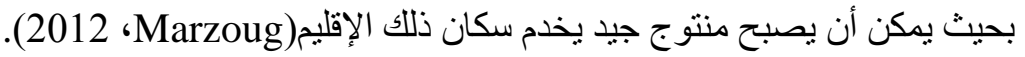

تعريف أحمد رشيد: هي تلك السياسات و البرامج التي تتم وفق توجهات عامة لإحداث تغيير مقصود ومرغوب فيه في

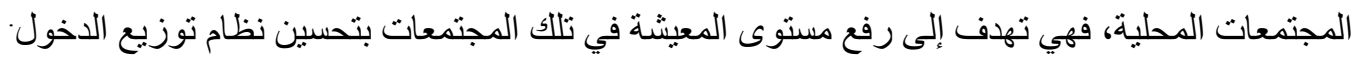

تعرف آرثر دونهام: هي نشاط منتظم لغرض تحسين الأحوال المعيشية في المجتمع، وتنمية قدارته على تحقيق التكامل

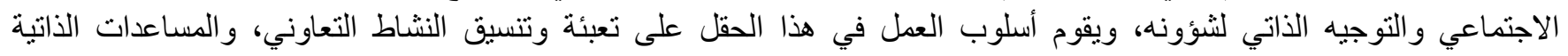
للمو اطنين، ويصحب ذللك مساعدات فنية من المؤسسات الحكومية و الأهلية ( ناجي، 2012).

استحوذت دراسات مواضيع التنمية على اهتمام الباحثين و المتخصصين وعامة الناس على حد سواء، بمختلف مستوياتها

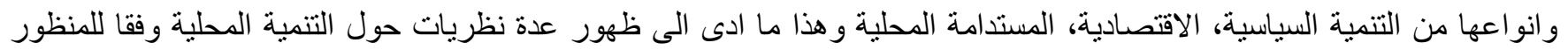
العلمي لكل باحث، فمنهم من اقتصر على الجوانب الاقتصادية، اخرون اهتموا بالجو انب السياسية، فظهرت عدة نظريات من اهمها: ـ المنظور الغربي للتنمية( تغريب التنمية). - منظور الاعتماد على التنمية المحلية. - منظور نظريات الحكم(الحكم الر اثند). ـ منظور المنظمات و المؤسسات العالمية .

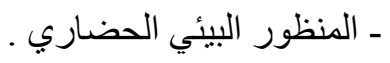
ـ منظور التحول الاجتماعي السياسي وغيره من الادبيات العلمية للتنمية.( عياد، 2016) 
في اطار المرسوم الرئاسي رقم 02-250 المؤرخ في 13 جمادى الأولى عام 1423 الموافق ل 24 يوليو سنة 2002

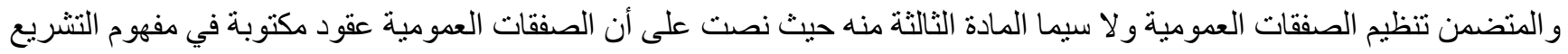

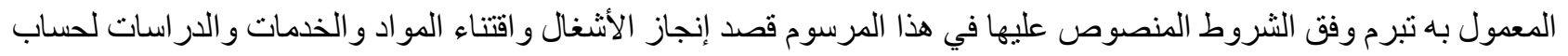

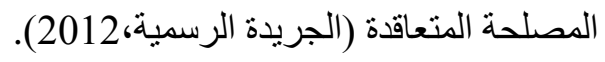
نلاحظ من هذا التعريف أنها تشمل احدى العمليات الآتية أو أكثر. ـ اقتناء اللوازم : مثل مو اد تجهيز أو منشآت انتاجية كاملة. - انجاز الأشغال. - تقديم الخدمات. - انجاز الدر اسات.

أما فيما يخص بصفقات استير اد المنتوجات و الخدمات التي تنطلب من المصلحة المتعاقدة المعينة الثرعية في اتخاذ القرارات

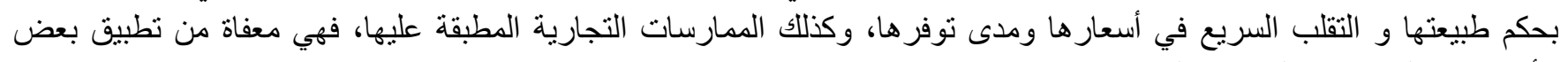

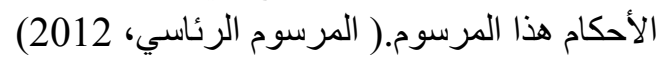

5.1. ان الأشخاص العموميين الذي يسعهم مجال تطبيق قانون الصفقات العمومية يمكن حصرهم فيما يلي: - مجمل الإدار ات العمومية للدولة. ـ الهيئات الوطنية المستقلة. - الو لايات و البلديات. ـ - المؤسسات العمومية ذات الطابع الإداري. ـ مر اكز البحث و التنمية. ـ المؤسسات العمومية الخصوصية ذات الطابع العلمي و التكنولوجي. ـ المؤسسات العمومية ذات الطابع العلمي و الثقافي و المهني.

ـ المؤسسات العمومية ذات الطابع الصناعي والتجاري، عندما تكلف هاته الأخيرة بإنجاز مشاريع استثمار ات عمومية بمساهمة نهائية

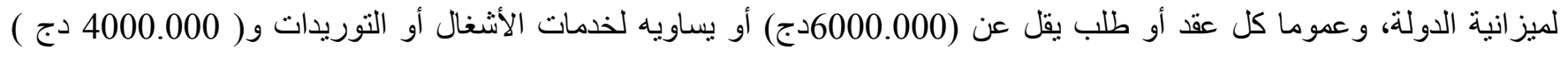

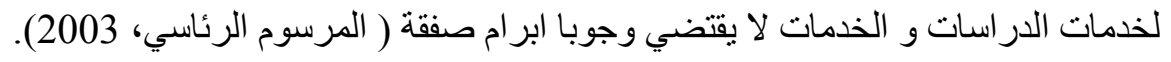

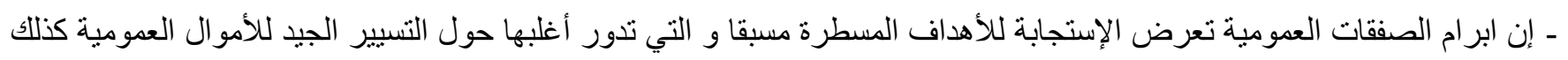

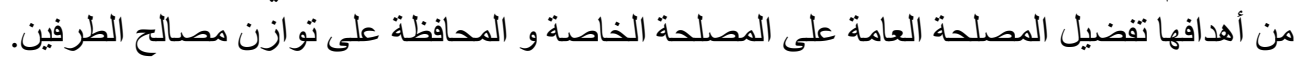
و تبرم الصفقات العمومية تبعا لنوعين من الإجراءات :

1- إجراء المناقصة: المناقصة هي إجراء يستهدف الحصول على عروض من عدة متعاقدين مع تخصيص الصفقة للعارض الذي يقدم

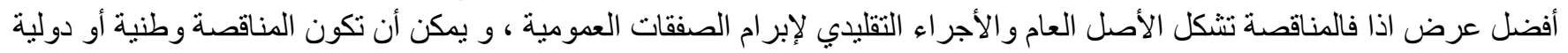
ويمكن تأخذ أحد الأشكال التالية (الجريدة الرسمية، لألاصل 2012): 
ـ المناقصة المفتوحة: وهي إجر اء يمكن من خلاله أي مترشح أن يقدم تعهدا.

- المناقصة المحدودة: وهي إجراء لا بسمح فيه بتقديم تعهدا إلا للمترشحين الذين تتوفر فيهم بعض الثروط الخاصة التي تتخذ ها المصلحة المتعاقدة مسبقا.

ـ الإستشارة الإنتقائية: هي إجراء يكون المترشحون المرخص لهم بتقديم عرض فيه المدعوون خصيصا للقيام بذلك بعد انتقاء أولي

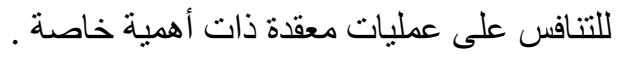

ـ المز ايدة: وهي إجر اء يسمح بتخصيص الصفقة للمتعهد الذي يقترح أحسن عرض، وتشمل العمليات البسيطة من النمط العادي ولا تخص الا المنرشحين الوطنين أو الأجانب المقيمين في الجز ائر.

- المسابقة: هي إجر اء بصنع رجال الفن في منافسة قصد انجاز عملية تشتمل على جوانب تقنية واقتصادية وجمالية أو فنية خاصة

(حمامة، 2004).

إن إجر اء المناقصة يمر بعدة مر احل يمكن تلخيصها فيما يلي :

1- مرحلة اقامة المنافسة بإثشهار الصفقة : عند إبرام المناقصة يجب اعتماد عدة مبادئ أهمها :

- مبدا المنافسة: تخضع المناقصات بصورة الزامية للمنافسة، وتعني بمبدأ المنافسة هنا هو إعطاء الفرصة لكل من توافر شروط المناقصة ليتقدم بعرضه للإدارة المتعاقدة.

و هذا لا يعني انعدام سلطة الإدارة المتعاقدة في تقدير صلاحية العارضين و كفاءتهم على أساس مقتضيات المصلحة العامة ، فالإدارة

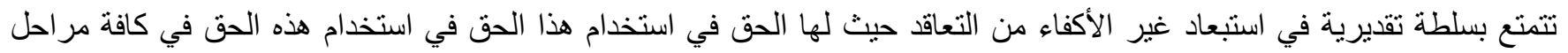
العملية التعاقدية و لكن حق الاستبعاد يكون بنصوص فالير فانونية.

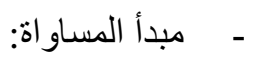

ان عن طريق تطبيق مبدأ المنافسة يتحقق مبدأ المساو اة بين المترشحين ، فالمساو اة أمام المرفق العام تقصي كل تفضيل في إسناد الصفقة و بالتالي يمكن اعتبار ها مصدر المنافسة.

لللك فاحتر ام المنافسة يعرض الزامية المعاملة المتماثلة لكل المعنين ، فالمساو اة اذا هي في نفس الوقت اساس المنافسة ووسيلة لخدمة

- مبدأ الإشهار: تخضع المناقصات مبدأ الإشهار الذي يعتبر وسيلة لضمان المنافسة، بدعوة المؤسسات للعرض، كما يعتبر الإشهار وسيلة لضمان الثفافية وبالتالي يعمل على احتر ام القانون الإن حمامة، 2004).

2- إجر اء التراض: بعد عملية الإشهار و إعطاء مهلة محددة للمعنين لتحديد مواقفهم اتجاه هذه المناقصة فإن على المهتمين أن يحرر

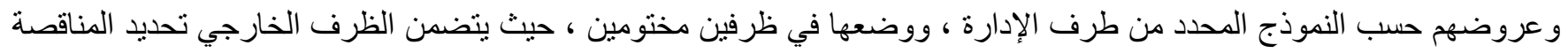

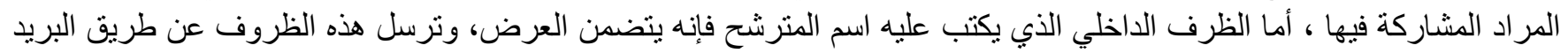
المضمون الوصول.

ويتم إيداع العرض في اجل يحدد تبعا لعناصر معينة تبعا لعناصره معينة مثل تعقيد موضوع الصفقة المعتزم طرحها و المدة التقديرية

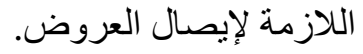

ومهما يكن أمر فإنه يجب أن يفسح الأجل المحدد المجال واسعا الأكبر عدد ممكن من المتنافسين، وفي هذه الحالة غير المصلحة

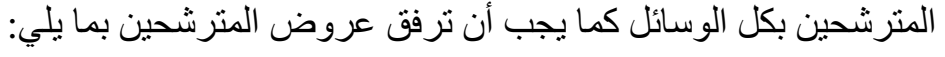




$$
\text { - يحرر العرض - يتصريح بالإكتاب. }
$$

ـ كفالة التعهد الخاصة بصفقات الأشغال و اللوازم التي لا يمكن أن تقل عن 1\% من مبلغ التعهد.

وترد كفالة المتعهد الذي لم يقبل، بعد خمسة وثثلاثين ( 35) يوما من تاريخ نشر اعلان المنح المؤقت للصفقة، كما ترد كفالة الصفقة

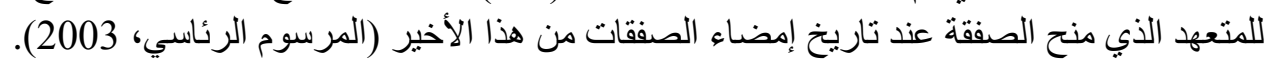

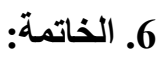

ـ تتطلب عملية بناء جهاز اداري محلي فعال ورشيد ليساهم في العملية التنموية السياسية الشاملة والمتوازنة.

- ضرورة اتخاذ اجر اءات حاسمة وجريئة لوضع استر اتيجية بديلة للتنمية الادارية، وهذا لن يتم الا بتأصيل الادارة و الانطلاق من فهم

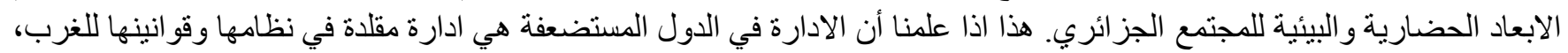

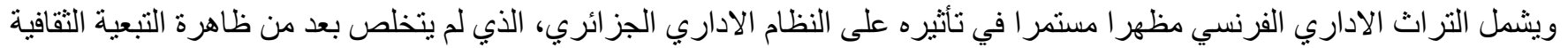

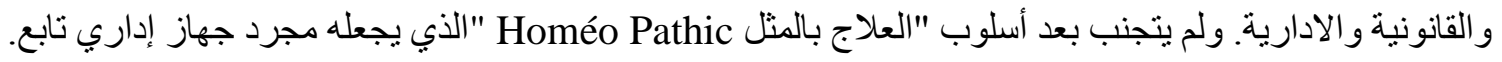

- وضع نظام للحوكمة المحلية الرشيدة معلن لكافة الاطر اف و الفو اعل. ـ البدء في التطبيق الفعلي لمبادئ الحوكمة المحلية الرشيدة.

ـ التقيد الصارم بمتابعة تتفيذ كل مر اسيم و قو انين المؤسسة للحوكمة المحلية الرشيدة على ارض الو اقع، مع التأكيد على الاستمرارية في

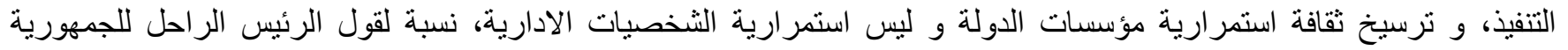

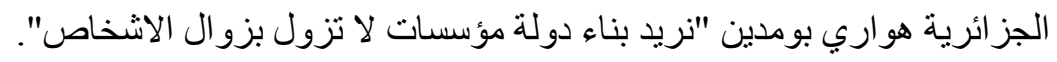

7.

$$
\text { [1] الجريدة الرسمية. (2002) عدد 52. الجزائر . }
$$

[2] الطيب، هاثمي. (2014). التوجه الجديب لسياسة التندية الريفية في الجزائر، برنامج تجديب الريفي 2006-2013. (رسالة دكتور اه). جامعة تلمسان .

$$
\text { [3] المرسوم الرئاسي ( 2002) ـ مادة رقم 02-250 ـ ـ الجزائر. }
$$

[4] حمامة، قدوج. (2004). عملية /برام الصفقات العدومية في القانون الجزائري. ديوان المطبو عات الجامعية.

$$
\text { [5] رشيد، احمد.(1981). نظربية الادرة العامة السياسة العامة والادرارة. دار المعارف. }
$$

[6] سندس، سعدي حسين. (2006). أثر حوكمة الشركات في التدقيق الداخلي. المعهد العربي للمحاسبين القانونيين.

$$
\text { [7] سيني، ليلى. (2016). الاتجاهات الحديثة لإصلاح بيروقر اطية الادارة. مجلة أكاديمي، } 182.3 .
$$

[8] عبد العال، طارق. (2005). حوكمة الثركات المفاهيم- المبادئ- التجارب تطبيقات الحوكمة في المصارف. الدار الجامعية.

[9] عبد النور، ناجي، (2012). نحو تفعيل دور الإدارة المحلية الجزائرية لتحقيق التنمية الثاملة، مجلة أكاديبيا، العدد 1. 96. [10] عدمان، مريزيق. (2015). التسبير العدومي بين الاتجاهات الكلاسيكية والاتجاهات الحديثة. جسور للنشر والتوزيع.

[11] عياد، محمد (2006). اثكالية العلاقة بين التنمية السياسية و التحول السياسي. مجلة أكاديبيا. العدد 1. 202. 


$$
\begin{aligned}
& \text { [12] كنزة، بر اهمية.(2011). دور التّدقيق اللّاخلي في تفعيل حوكمة الشركات دراسة حالة مؤسسة الدحرّكات" EMO الخروب } \\
& \text { ولاية قسنطينة (رسالة ماجستير في علوم التسيير). جامعة قسنطينة } 2 . \\
& \text { [13] منصور ، عبد الله، بزاوية، عبد الحكيم. (2008). اهدية تطبيق مبادئ الحوكمة في التنظبيات الهؤسساتية للزكاة، مركز }
\end{aligned}
$$

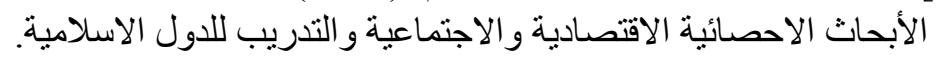

[14] Marzoug.M. and Kouadzia .N and Amara. F. (2012). Gouvernance urbaine et développement local en Algérie quels enjeux pour les métropoles régionales: Cas annaba.

Revue des sciences [ الحكم الحضري والتنمية المحلية في الجزائر ما هي تحديات العو اصم الجهوية: حالة عنابة ] humaines. Université de Mohamed khider Biskra. 